\section{Survey of vaccine administration to splenectomized patients: Are guidelines being followed?}

\section{To the Editor:}

Asplenic patients are at risk for developing overwhelming postsplenectomy infection (OPSI), in particular with encapsulated organisms, such as Streptococcus pneumoniae, Neisseria meningitidis and Haemophilus influenzae type B (Hib) (1). Vaccination against these organisms substantially decreases the risk of infection, and is considered the standard of care in these patients (2). The sixth edition of the Canadian Immunization Guide (3) recommends polysaccharide pneumococcal vaccine for all asplenic individuals who have not been previously immunized. A single booster five years after initial vaccination is recommended. Individuals should also receive Hib conjugate vaccine and immunization for meningococcal disease (3).

Despite these guidelines, studies have reported low adherence to the recommendations. Ramachandra et al (4) reported that $72 \%$ of 76 splenectomized patients received the pneumococcal polysaccharide vaccine, 59\% received $\mathrm{Hib}$ and only $39 \%$ received the meningococcus vaccine (4). A Canadian survey (5) reported that 111 of $164(68 \%)$ patients received the pneumococcal vaccine during hospitalization for splenectomy, only four received $\mathrm{Hib}$ and two received the meningococcal vaccine. A Scottish study (6) of 974 splenectomized patients reported data on vaccination status for $73 \%$ of patients, with only $47 \%$ of patients having received all three vaccinations.

We undertook a review to determine whether splenectomized patients at our institution were receiving the appropriate vaccinations and were being counselled about the risk of OPSI. All patients who underwent a splenectomy between January 2002 and December 2004 at the Queen Elizabeth II Health Sciences Centre in Halifax, Nova Scotia, were included. Information was collected on age, sex, indication for splenectomy, receipt, timing and documentation of vaccinations, documentation of the surgical discharge summary including report of the splenectomy, documentation of administered vaccines, recommendations for future vaccines, recommendations for Medic Alert bracelets and counselling about the risk of OPSI. In addition, a letter was sent to general practitioners of living patients requesting details about the administration of vaccines outside the hospital if these data were not available from hospital records. If no response was received after the first letter was mailed, a second letter was mailed six weeks later. If patients had not received all recommended vaccinations, a subsequent letter was sent to the general practitioner so that they could arrange for vaccine administration according to the current standard of care.

Of 70 patients reviewed, 28 (40\%) were male and were between 17 and 84 years of age (median age 53 years). The most common indication for splenectomy was idiopathic thrombocytopenic purpura $(n=28)$. Other indications included trauma $(n=13)$, hemolytic anemia $(n=7)$, thrombotic thrombocytopenic purpura $(n=3)$ and other causes $(n=19)$. Five patients who had died were excluded from the analysis because of incomplete information.

The response rate from general practitioners was $94 \%$. Vaccination had been received by $91 \%$ of patients for S pneumoniae, $75 \%$ for $N$ meningitidis and $68 \%$ for Hib. However, only $27 \%$ of surgical discharge summaries included documentation of vaccine administration or recommendations for future vaccinations. Only $6 \%$ of discharge summaries documented the risk of infection postsplenectomy and that recommendations were given to patients about this risk.

Vaccination rates at our institution are better than previous reports. However, some patients are still not receiving the recommended vaccinations, particularly for $\mathrm{Hib}$ and $\mathrm{N}$ meningitidis. Implementation of an institutional standing order for the administration of vaccines may improve vaccination rates and should be evaluated. Although our vaccination rates are relatively high, the documentation regarding vaccinations, recommendations for follow-up vaccination and documentation about the risk of infection in the surgical discharge summary was lacking for most patients. Further studies are planned in our institution to assess the usefulness of a 'checklist' to improve these deficits.

Andrea K Kew MD, Darrell White MD, Division of Hematology, Department of Medicine

Kathryn Slayter PharmD, Division of Infectious Diseases, Department of Medicine, Department of Pharmacy, Dalhousie University and Queen Elizabeth II Health Sciences Centre, Halifax, Nova Scotia

\section{REFERENCES}

1. Sumaraju V, Smith LG, Smith SM. Infectious complications in asplenic hosts. Infect Dis Clin North Am 2001;15:551-65.

2. Lynch AM, Kapila R. Overwhelming postsplenectomy infection. Infect Dis Clin North Am 1996;10:693-707.

3. National Advisory Committee on Immunization, Health Canada. Canadian Immunization Guide, 6th edn. Canadian Medical Association, 2002.

4. Ramachandra J, Bond A, Ranaboldo C, Cullis J. An audit of post-splenectomy prophylaxis - are we following the guidelines? Ann R Coll Surg Engl 2003;85:252-5.

5. Brigden ML, Pattulo A, Brown G. Pneumococcal vaccine administration associated with splenectomy: The need for improved education, documentation, and the use of a practical checklist. Am J Hematol 2000;65:25-9.

6. Kyaw MH, Holmes EM, Chalmers J, Jones IG, Campbell H. A survey of vaccine coverage and antibiotic prophylaxis in splenectomised patients in Scotland. J Clin Pathol 2002;55:472-4. 


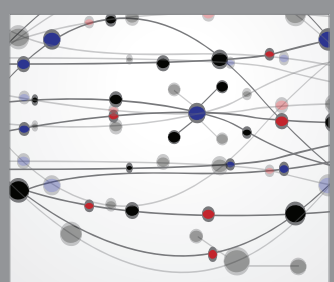

The Scientific World Journal
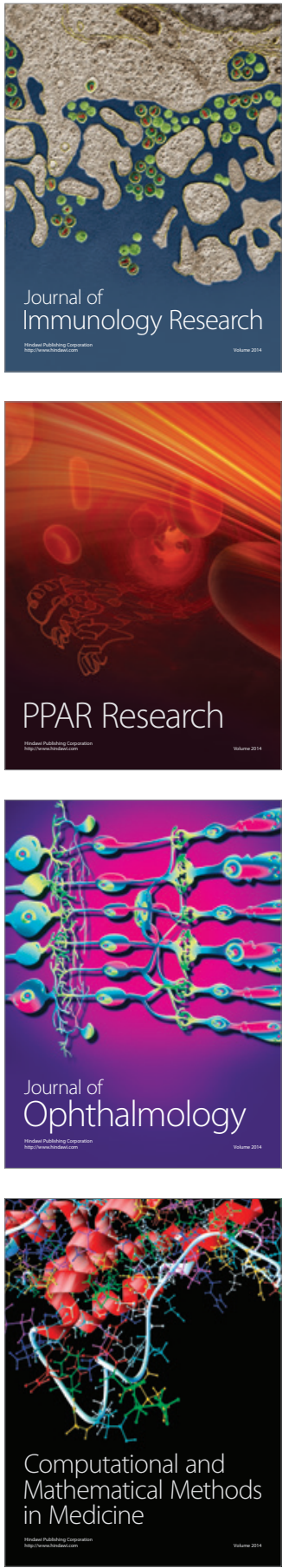

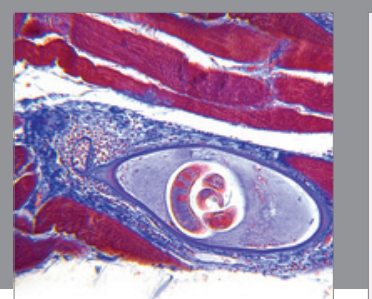

Gastroenterology Research and Practice

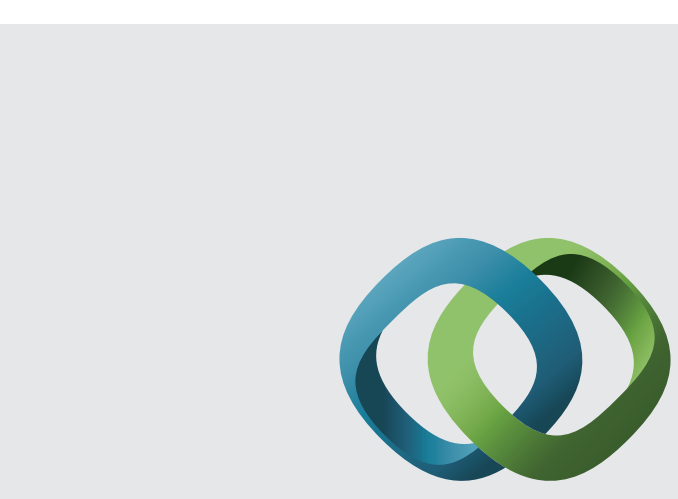

\section{Hindawi}

Submit your manuscripts at

http://www.hindawi.com
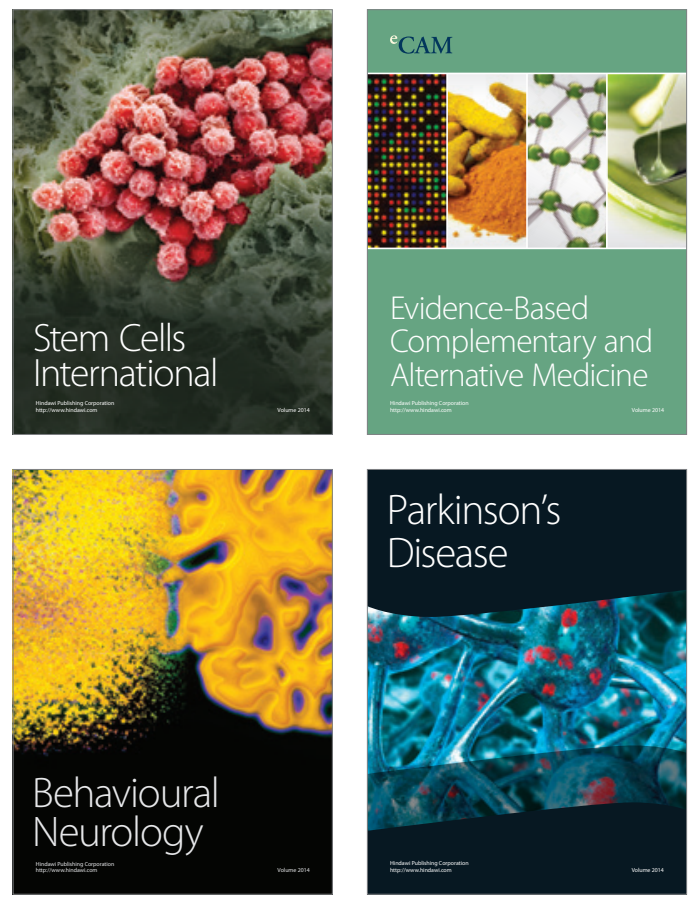
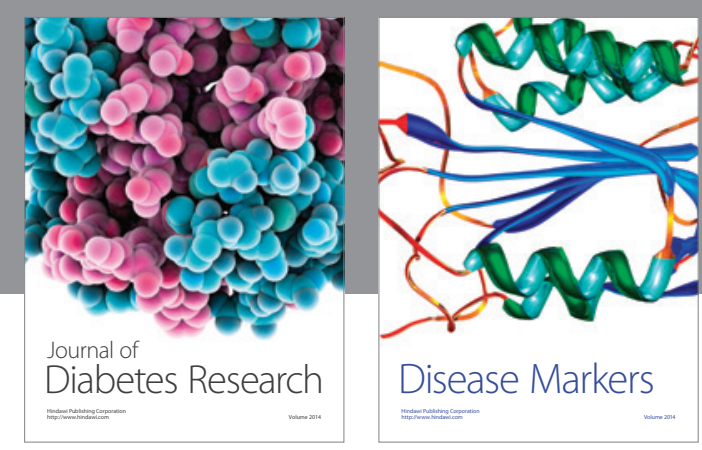

Disease Markers
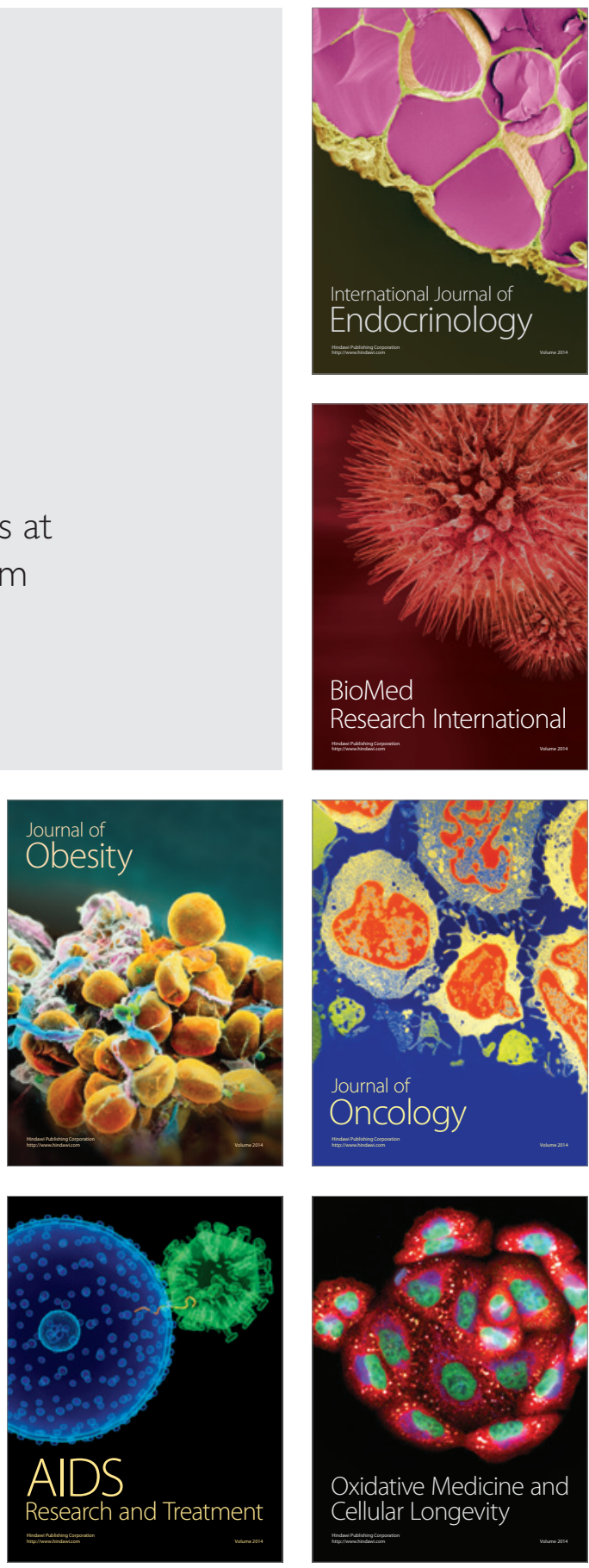